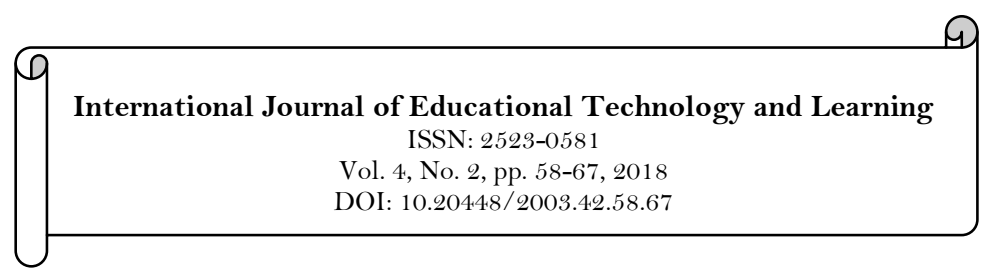

Cupdates

\title{
"English for Academic Purposes in the Korean University Context: Teachers' Opinions on What is Being Taught, How it is Being Taught, and Possible Improvements"
}

\author{
Chris Kobylinski ${ }^{2}$ \\ Richard Prasad ${ }^{2}$ \\ ${ }^{1}$ Communicative English at Hanguk University of Foreign Studies in Seoul, South Korea. \\ Email:chriskoby@gmail.com \\ ${ }^{2}$ College of English Education Committee at Hanyang University in Seoul, South Korea.
}

\begin{abstract}
As the use of English in the academic world increases around the world, English for Academic Purposes (EAP) continues to grow. The increase in demand for EAP courses and teachers often finds English teachers having to prepare students to study in fields that they themselves might not be familiar with or teach a style of course they might not have done before. In addition to these obstacles, there are many institutional barriers that prevent teachers from teaching EAP properly. This paper examines these problems in the South Korean university context. Currently many Native English Speaking (NES) English teachers are transitioning from teaching Commutative Language Teaching (CLT) classes to teaching EAP courses and are experiencing many problems and barriers as they transition and teach EAP. 10 NES university teachers were interviewed in order to gather qualitative data about their experiences in teaching EAP courses in an attempt to better understand the current situation in many Korean universities. The data gathered revealed many similar problems and led to ideas for possible improvement on many levels.
\end{abstract}

\author{
Keywords: \\ EAP \\ EFL \\ ELT \\ ESP \\ CBI \\ CLT \\ Korea. \\ Licensed: \\ This work is licensed under a \\ Creative Commons Attribution \\ 4.0 License. \\ Publisher: \\ Scientific Publishing Institute
}

\section{Introduction}

English for Academic Purposes (EAP) "refers to the language and associated practices that people need in order to undertake study or work in English medium higher education" (Gillett, 2011). While EAP is a separate field in ELT (English Language Teaching) because of its emergence out of English for Specific Purposes (ESP), it retains several key commonalities with Communicative Language Teaching (CLT), which has given both some shared goals, albeit in different communicative contexts. CLT and EAP share a goal of communicative competence (Richards, 2006; Savignon, 2007); for CLT this has grown out of an emphasis on providing situations where learners needed language in meaningful ways, through interaction and for social purposes (Alexander, 2012), while for EAP such communication occurs in the context of academic discourse in disciplines of study, with very different expectations and conventions (Hylandd, 2006; Hylandp \& HampLyons, 2002; Hylands, 2018). While CLT and EAP both share a broad focus of language function over form, the emphasis is on oral proficiency for CLT (Alexander, 2012) while for EAP the focus is to develop in learners "communication practices [that] reflect different, disciplinary-oriented ways of constructing knowledge and engaging in academic study" (Hylands, 2018). In order to ensure the needs of such learners are addressed, ESP (like CLT) has grown out of the recognition that there are "different ways in which learners acquire language and ... differences in the ways languages are acquired" (Gillett, 2011). ESP was defined as needs-based, and these defining characteristics (Dudley-Evans \& St John, 1998) later came to be the foundation of EAP. As ESP and later EAP have refined their methodologies and gained currency, at the tertiary level in particular a shift has occurred towards the more specific focus of EAP on academic discourse (Anderson, 2014). Thus, while CLT and EAP are related to each other, there are some key differences, which have impacted the way EAP courses have been adopted and adapted, and which has often made the transition from CLT to EAP a difficult one. 
Given this backdrop, the focus of this study is this transition at the tertiary level in South Korea. As Korean universities try to shift the focus from general CLT classes to more specific EAP courses, difficulties have arisen on many levels that have prevented teachers from truly teaching EAP courses as they should be taught. Many of these obstacles in transitioning from CLT courses to EAP courses at Korean universities are similar to other issues addressed outside of Korea, but a number of the problems are unique to the Korean setting and need to be further explored. While many Korean university administrators might think that simply changing the course title makes a CLT course an EAP course, many teachers often struggle to truly provide their students with authentic EAP course for a variety of reasons. Because of institutional policies and procedures, teachers have often found themselves constrained by these limitations on how they can implement EAP courses, and many are often unable to truly do so because of a variety of issues ranging from departmental policies, class enrollment, mandatory text books, and a lack of knowledge and collaboration with department faculty about the skills or content expected to be taught.

This paper first outlines the goals and critiques of EAP as they relate to the Korean context, then highlights some of the particular issues raised in previous research on the transition from CLT to EAP (Kwon, 2012; Lee, 2014; Seong, Chang, \& Kim, 2007). In this case study 10 Korean university teachers were interviewed to get a general idea of the current situation in instructing EAP in Korea, to gain insights into teacher beliefs and practices, and see what type of courses were being taught and if these courses could be delivered effectively. The qualitative finds of these interviews were then used to analyze possible avenues for implementing EAP courses more effectively, informed by current research in EAP practice.

\section{Literature Review}

\subsection{Definition - What is EAP?}

Globalization has brought with it the spread of English learning and English Language Teaching (ELT). As a result, at the tertiary level, instruction in English as a Second Language (ESL) and English as a Foreign Language (EFL) have undergone considerable changes in recent years. The spread of English for professional and academic use has brought with it a gradual shift away from General English (GE) instruction, and the growth of the field of English for Specific Purposes (ESP). The context of English education at the tertiary level has evolved, as countless students and academics seek to gain fluency and make contributions in the type of academic English their fields require, and as universities across the world expand their course offerings in English for domestic students and open their doors to international students. As an offshoot of ESP, English for Academic Purposes (EAP) finds itself at the heart of this expanding sphere of English education.

"English for Academic Purposes refers to language research and instruction that focuses on the specific communicative needs and practices of particular groups in academic contexts" (Hyland, 2002). This definition is based on earlier sources (Flowerdews \& Peacock, 2001) which express the goal of EAP as teaching English with the aim of facilitating learners' study or research in that language. This definition reflects the core ideal of making language "purposeful by relating it to credible real-world outcomes" (Hylands, 2018), as well as "communicative competence" (Alexander, 2012), goals that EAP shares with Communicative Language Teaching (CLT).

EAP is also considered to have grown out of the broader field of ESP (Basturkmen, 2010). EAP owes much of its approach and character to ESP (Hylands, 2018) with their common ideals stemming from DudleyEvans and St John's "absolute characteristics" - meeting learner needs, focusing on methods and activities of particular disciplines, and being "centered on the language....skills, discourse and genres" of these disciplines (Dudley-Evans \& St John, 1998). Like ESP, EAP is explicitly driven by learner communicative needs in specific contexts. This includes "identifying the specific language features, discourse practices, and communicative skills of target academic groups, and which recognizes the subject-matter needs and expertise of learners" (Hylandd, 2006) with "needs analysis as a systematic way of identifying the specific sets of skills, texts, linguistic forms and communicative practices that a particular group of learners must acquire" (Hylands, 2018). Reflecting its specific purpose of meeting academic needs, EAP is also concerned with facilitating students' access to the ways of constructing knowledge and discourse in their disciplines, and "engaging them in a critical understanding of the increasingly varied contexts and practices confronting them" (Hylands, 2018).

\subsection{Goals of EAP - Needs Analysis, Syllabus Design, and Teacher Practices}

If EAP instruction is intended to embody these ideals, then EAP requires an approach that presents such discipline-specific content to learners, promotes their access to the structure and content of texts, empowers them to critical assessments of such content, and facilitates learner production that encompasses these objectives. Needs analysis and syllabus design are thus central to the field, key steps in the process of identifying the specific objectives that EAP courses are based on, in selecting texts for content, and in shaping the practices of EAP instructors. In order to create the ideal EAP course, teachers must reflect upon what this ideal should be, and this ideal requires the teacher to approach the course through a variety of roles. Belcher (2006) believed that this required the EAP teacher to wear many hats, to be 'the E $[\mathrm{A}] \mathrm{P}$ ideal: combined needs assessor, specialised syllabus designer, authentic materials developer, and content-knowledgeable instructor, 
capable of coping with the revolving door of content areas relevant to learners' communities' (Belcher, 2006). In order to achieve the ideal, teachers must be willing to access their students' needs, design a syllabus and materials to meet those needs, and then be able to deliver the course effectively.

Needs analysis is "the process of discovering that what and how of the course" (Dudley-Evans \& St John, 1998) a broad approach that includes needs of the discipline, the target situation ie. "the tasks and activities learners are/will be using English for" (Dudley-Evans \& St John, 1998) as well as learner needs, which relate to their communicative competencies, knowledge of discourse related to their fields, as well as individual motivations related to these objectives and content.

Following this satisfaction of the context in which the EAP course is situated, teachers must then look at the students they are teaching and figure out what they will need to succeed in future courses or endeavors. This might sometimes be difficult for the teachers, because they are usually language teachers with a background in CLT, and might lack familiarity with some of the subjects that their students are studying. As Alexander (2012) points out, "some teachers believe that teaching EAP involves simply applying their current expertise to new materials and contexts, rather than embracing a new paradigm and developing towards" the ideals of instructional practice in EAP. Despite the lack of familiarity with some of the subjects, teachers should prepare their students for success in their future studies and strive to create the ideal EAP course, a commitment that Hyland refers to as "require[ing] the jack-of-all-trades EAP practitioner to become a specialist in the discourses of particular disciplines" (Hylands, 2018).

If EAP is considered to be a "text-oriented approach"(Hylands, 2018) which uses teaching materials to for raising awareness of discourse features, selection of such materials requires a balance of content and teaching approaches which serve to motivate (Nakano \& Kusada, 2010) and scaffold learner engagement (Wette, 2014; Wingate, 2012). One common element that is essential to course design and materials selection is the use of model texts. The use of modeling and model texts has been shown to be effective in teaching EAP writing (Wette, 2014) but when EAP teachers take on the role of materials developer, they must decide what type of model should be used in their course. Wingate (2012) believed that student models helped students to learn the structure, and that the use of student texts may allow the students to see the variety that exists within these structures. Wette (2014) found that teachers use of modelling in the form of both exemplary and flawed text helped students understand the process of writing. She also stated that modelling helped to combined many elements of the curriculum and that the authentic models provided students with learning opportunities.

While the use of student texts is important, EAP, must not disregard the use of authentic texts (Hylands, 2018). Anderson (2014) also stressed the need for collaboration in selecting authentic texts. He stressed that EAP teachers must be effective course designers that know the content and how to approach the content of the authentic texts that are needed in EAP courses. Thus, in designing courses, EAP teachers must consider how these models can be used and not shy away from using authentic texts that might be slightly unfamiliar to them. Instead of shying away, teachers should embrace and familiarize themselves with these authentic texts.

Finally, EAP teachers have to set out to create an ideal EAP course, not just expect it to occur naturally. Chan (2018) outlined the process of creating an ideal syllabus and managing course design. While taking on the role of needs accessor and syllabus designer, teachers need combined needs design and input from the real world to create syllabi. As materials developer, the selection of discourse targets, inclusion of student and authentic models of texts, and a "delicate scaffolding" (Wilson, 2016) of activities of inquiry to help learners access content. Although every course might be different, these steps can be applied to all EAP courses, and teachers must be willing to take on more roles, which include accessing the needs, designing an effective syllabus, choosing appropriate materials, and most importantly, delivering an effective course while in the classroom.

\subsection{The EAP Ideal - The Discourse Community}

In practice, while the hard yards of creating EAP courses are crucial, fundamentally EAP as a practice is not a product, but an approach. Hutchinson and Waters called ESP an approach to language learning, which is based on learner need" as cited in Falaus (2017) and EAP shares this approach to language education with ESP - being "based on identifying the specific language features, discourse practices, and communicative skills of target academic groups, and which recognizes the subject-matter needs and expertise of learners" (Hylands, 2018). Instruction and teaching content is explicitly matched to the language, practices and needs of the learners (Gillett, 2011). Ideally, teachers try to identify texts which contain target discourses, and encourage students to engage analytically and develop a critical understanding of the contexts in which these discourses are used (Alexander, 2012) and helping learners develop "an understanding of the cognitive, social and linguistic demands of specific academic disciplines” (Hyland, 2002). This means that EAP as language education also recognizes learners as a part of the discourse community of their fields, and that "engagement ... involves new ways of behaving, interacting and thinking" with content and discourse as a "social practice" (Hylands, 2018).

This value, then, can be extended to "giv[ing] students access to ways of knowing: to the discourses which have emerged to represent events, ideas and observations in the academy" as well as "engaging them in a critical understanding of the increasingly varied contexts and practices confronting them" (Hylands, 2018). 
This represents a fundamental higher-level goal of EAP as education, to equip learners with the tools to assess, evaluate, criticize and add their own understandings to the discourses of their fields (Hylandp \& HampLyons, 2002).

\subsection{Issues \& Criticisms Facing EAP}

Precisely whether EAP in practice can accomplish such goals is the theme of several lines of criticism. In his overview of the state of EAP, Hyland outlines claims against both the premise and substance of EAP, on the basis of pedagogy, student proficiency, and institutional priority (Hylands, 2018).

Despite its emphasis on being "situated" in context (Benesch, 2001) EAP has itself become split into two somewhat contradictory arms, identified as English for General Academic Purposes (EGAP) and English for Specific Academic Purposes (ESAP). ESAP is "referred to as a subject-specific approach ... focus [ing] the learners on language skills specific to a particular subject of study" and utilizing authentic texts and discourse (Anderson, 2014). EGAP on the other hand, also known as a common-core approach, "involves the acquisition of general academic language, as well as study skills including strategies for reading, writing, speaking and listening effectively' (Anderson, 2014). From the perspective of proponents of EAP, a significant issue is the impact this notion of 'common core' has had on teaching approaches, especially given the recent transitions that have been made across ESL and EFL. Hylands (2018) describes one criticism of the current state of $\mathrm{E}(\mathrm{G}) \mathrm{AP}$ as "focusing on study skills and isolated texts". This has influenced the shape of EAP instruction, resulting in what critics of EAP claim is "a focus on generic skills such as paraphrasing, note-taking and skimming and scanning, and on register-level language features," which in turn compels students into the role of "passive recipients of knowledge ... [who] mimic expert practices rather than engage as active learners" by helping students acquire "a new literacy and ... new discourse practices" in their communities (Hylands, 2018).

Other criticisms of EAP stem from perceptions of learners and teacher beliefs. According to Alexander (2012), some teachers believe that teaching EAP involves applying their familiarity and experience with CLT methods to EAP contexts, rather than acknowledging the broader roles of an EAP instructor. In assessing teacher beliefs towards lower-proficiency learners, Alexander also finds misconceptions about the need for higher proficiency to benefit from EAP instruction, based on the perception that language is acquired "incrementally" in a "step-by-step process" (Hylands, 2018). Thus, critics have argued that the role for EAP best serves higher proficiency students rather than acknowledging second language acquisition theory which posits that learners are capable of acquiring language structures as they need them (Hylands, 2018), and that based on this principle EAP seeks to empower learners to "interact with authentic texts from their disciplines ... through their current level of competence [supported] by instructional scaffolding" (Alexander, 2012).

The final factor acting against the view of EAP in academia is that it is little more than a remedial service, a position which "relegates it to the fringes" of university curricula, seen as a form of study skills instruction or as a remedial support service instead of being seen as capable of contributing to core departments (Hylands, 2018). The role of EAP is undergoing a further "downgrading" (Anderson, 2014) as an increase of teaching hours, and budgets and shifting attitudes has led to a questioning of the need for such courses.

All of these factors play in important role in views of EAP and the niche that EAP has come to occupy in Korea. These criticisms of the fundamentals of EAP have had real manifestations in Korean university classrooms. When faced with the challenges of heterogeneous classrooms, as well as top-down determined course objectives and materials, teacher beliefs and practices have been challenged. These have had a substantial impact on EAP course design in the Korean context, as outlined below.

\subsection{Korean Context}

EAP, specifically the notion of EGAP, has gained currency and has become an important paradigm for the design of EAP courses in practice in the Korean tertiary context. Anderson (2014) outlines how the emergence of EAP from ESP was due to "large increases in foreign students entering universities in 'English speaking' countries" as well as universities outside of those countries "which began to offer courses taught in English" these factors are both important contributors in the Korean context. ELT at the tertiary level in Korea had emphasized GE to improve student proficiency until relatively recently, but the transition to EAP has become a priority. This shift has come about because of an increasing emphasis on practical courses, with many in academic circles calling for more of such courses (as well as in ESP) to improve students' English skills for their academic and professional careers (Chang, 2009; Seong et al., 2007).

Arguments for making the transition from GE to EAP/ESP begin with the claim that while both "share a similar aim: to develop the students' communicative competence" (Basturkmen, 2010) EAP and ESP "address ... the students' more specific needs' (Lee, 2014), including academic achievement. Studies by Seong et al. (2007) and Kwon (2012) cite a need for an ESP-oriented curriculum "to reflect students' needs related to their majors and future jobs" (Lee, 2014). Basturkmen (2010) makes the additional claim of the effectiveness of ESP over GE because specifically defined learning objectives are more likely to be achieved when learners are more highly motivated - in this case by the perceived needs and benefits of learning English for their fields. Despite all this, Lee concedes that there is no study which "successfully justifie[s] the need to change GE to $\mathrm{ESP} / \mathrm{EAP}$ ” in the Korean context (Lee, 2014). 
Concurrent with this has been the increase in English-medium Instruction (EMI) classes, which builds on the theoretical premise of the "urgent need for content learning" which leads to "language education taking place more meaningfully and successfully" (Lee, 2014). While EMI is focused on content-learning, this has raised the issue of the role of CBI in introducing content with the requisite language skills. Song (2006) concludes that CBI does benefit ESL instruction, but Lee (2014) points out that EMI courses in Korea pose significant burdens for professors (as well as their negative perceptions of their students' language and content knowledge) and students (on the development of their proficiency. The attitudes of faculty towards providing language support and skills instruction to learners are also typical of many other countries (Hylands, 2018) such support is very limited. Nonetheless, for a variety of government and institutional pressures, universities in South Korea have embarked on a large-scale transition towards EAP/ESP, usually through dedicated departments that face numerous limitations in implementing courses.

These pressures have led to fundamental questions over the nature of EAP courses that are being offered, that essentially are EGAP courses, with little direct relevance to students' majors. The rise in EMI course offerings are motivated by government university rankings as well as to emulate pre-eminent schools (Lee, 2014), and are not accompanied by CBI courses (or ESAP courses) to support students' needs. There is little evidence of needs analysis to determine what students may need English for in their majors in designing these courses, nor is input sought from instructors as to their content or objectives. As a result, these EFL departments are tasked with teaching courses that are regarded as truly "residing on the fringes" of universities' curricula (Lee, 2014). In this context, then, this study sought to survey the range and scope of courses designated as EAP courses in Korea, and outline the obstacles to improving and teaching such courses more effectively.

\section{Subjects}

The subjects of this study were a convenience sample of 10 native English speaking (NES) university teachers, 7 instructors who were teaching undergraduate EAP-style courses (N, K, J, R, M, T, and L) and $3(\mathrm{~A}$, $\mathrm{D}$, and S) teaching graduate level courses (it should be noted that $\mathrm{A}$ and $\mathrm{D}$ also taught undergraduates at their universities.) The teachers had been teaching at the tertiary level in Korea for a minimum of 10 years. Each teacher had taught a range of courses ranging from general conversation to EAP.

The teachers taught at various types and levels of university and represented a large portion of the type of course that many NES Korean university teachers teach. Although this wasn't a random or large sample, it was a diverse sample that highlighted many of the common issues and problems that a large number of Korean university teachers face when teaching EAP courses.

\section{Methodology}

The teachers were interviewed separately over a period of one month. They were interviewed during a semester break, with the hope that the classes they taught and the improvements they wished to make for the next semester would be fresh in their minds. The teachers participated in semi-structured interviews to get an overview of their educational environments and how they felt these related to the overall goals of EAP instruction. The data gathered was qualitative in nature, from which common themes of course design and implementation, and teacher practices and opinions were compiled to gain a broader understanding of the Korean teaching context. The interviews were divided into three sections: the course in theory, the course in practice, and recommendations for improving the course.

The first part of the interviews was designed to figure out who the teachers were teaching and what the course objectives were. The questions were asked to determine which grade, level, and majors were being taught. Follow up questions explored if the teachers were teaching mixed grade, level, and major classes or classes that were more homogeneous. Teachers were also asked to describe the type, scope, and sequencing of the course, along with what resources that were used to teach the course. They also were asked to describe the course objectives. Follow up questions were asked to see how much control teachers had over the course design, objectives, and resources.

The second part allowed the teachers to reflect upon how the class they taught matched the course description and objectives. If the teachers didn't feel that the course being taught matched the description and objectives, they were asked about what barriers prevented them from doing so. In this part teachers were also asked about what type of supplemental materials were used and how they taught specific skills. They were also asked if they used certain techniques such as modeling.

In the final part, all teachers were also asked to analyze the needs of the students and asked how they would and could make the courses better. They were prompted to consider the needs of the students and how this course prepared them for future courses. Teachers were also asked if improvements should be made to the course and follow-up questions were asked to determine what improvements or what barriers prevented these improvements from being made. The information given in these interviews was collected and analyzed and a few common overarching ideas emerged that shed some light onto what was being taught and how it compared to what should be taught. 


\section{Findings}

The interviews revealed many interesting patterns and similarities. In regard to the course in theory, one of the most common issues that was brought up was that although most courses were listed as EAP courses, many of the courses weren't actually designed as EAP courses. Among the undergraduate teachers, 2 instructors taught courses that fell under the realm of EAP - one was charged with EGAP courses based on a standardized format, while the other had more leeway to tailor courses to the academic needs of specific majors. The course objectives and resources were chosen by the school or the department for the majority of the teachers. As a result, only one of the teachers felt that they had some ability to teach the course as they saw fit and only two were allowed to choose the materials or text book for the course. Most of the teachers, 6 out of 7 , at the undergraduate level were teaching classes of mixed majors. In addition, some of the other teachers felt that their courses were designed to use content to facilitate a more theme-based, or tasked-based approach to language, rather than being more of an EAP-style course. $\mathrm{N}$ observed that while the published textbook did provide texts based on corpus research for particular fields, in practice these texts were utilized more for discussions rather than for general academic skills. $J$ and $\mathrm{K}$ however, utilized similar coursebooks for the specific instruction of general academic skills. Most considered (with the exceptions of A and D) that there was little support for content in the students' area of studies, and several teachers felt that this was a barrier to helping students prepare for future courses in their field ( $\mathrm{R}$ for example heard this from several students in discussions about how an EGAP course can benefit them.) However, some acknowledged that where academic skills and formats could be taught and applied, it served to benefit some of the students. Among the undergraduate instructors, A referred to academic genres and discourse in courses, but only to a limited extent, and D was the only one who was able to instruct and assess specific aspects of academic discourse for particular majors.

The graduate level teachers (A, D and $\mathrm{S}$ ) faced a slightly different situation, with courses spanning a range of different designs and outcomes, from CBI to ESAP. Two out of three graduate school teachers (A and S) did teach classes comprised of students from a single major, and the graduate school teachers had more freedom to create their courses. Two of the teachers (S and D) had freedom to design their course as long as it matched the course objectives, and A was given complete freedom. For S, however, despite this greater freedom, these courses were more CBI style courses, intended to support proficiency rather than content in other courses, while the other graduate instructors (A and D) did lead ESAP courses that were specifically designed to assist students with the demands of academic writing.

When it came to teaching the course, many of the undergraduate teachers shared common approaches and techniques although the courses were taught in various ways. One of the most common methods that was used by all of the teachers was that of using model texts for teaching writing. All teachers said they either used models from the text book or brought in student models or exemplar models to demonstrate expectations to students. It should be noted that only 1 of the undergraduate instructors utilized student examples as models (both A and D, who instructed both levels, also used these student model texts.) While the range of the models and structures varied from simple sentences at the lowest levels to academic essays, and even referencing, all teachers felt that the use of models was helpful - here it is important to note that only a few instructors indicated that models including referencing were featured in undergraduate courses. Although a few teachers did worry that students only copied the structure, most teachers felt that models helped the students to learn what was expected, but didn't limit them from moving beyond the model and expressing themselves. A few of the undergraduate school teachers also used models for teaching presentations or other skills ( $\mathrm{R}$ utilized such models in the in-house published textbook, for example), but most felt there should be more support especially for writing - in the case of $\mathrm{J}$, the coursebook used lacked sufficient content to adequately model essay structure, and $\mathrm{N}$ mentioned that the writing models did not really fit an academic purpose.

The graduate school teachers also used authentic models for teaching writing, for both the CBI and ESAP courses. Both ESAP instructors (A and D) supported writing instruction with authentic texts, examples and examinations of student writing that were focused on discipline-specific discourse. S, the instructor of CBIbased courses also used models for other skills, such presentations, discussions, and debates. One common theme from both levels was that the teachers thought that the use of authentic models was very important and beneficial to teaching skills, specifically writing skills.

The final part of the interviews, the section about improvements and limitations preventing improvements was the most interesting and revealed diverse perspectives from all teachers. One of the common problems that most teachers faced, especially at the undergraduate level, was the issue of teaching students from mixed majors and teaching students of various levels and abilities. While some research argues that EAP is useful for lower level students, most of the teachers interviewed felt that it was difficult to teach academic skills to students with low proficiency, and three even mentioned that they thought lower level students should take a different style of course (N, R and $J$ ) because of the difficulties these students faced in participating in class tasks. In addition, another problem raised by four of the teachers that relates to having students of mixed ability in the same course was the mandatory use of a strict grading curve. Most Korean universities have a mandatory grading curve, and some of teachers ( $\mathrm{R}$, for example) saw this as an obstacle to fair assessment, with proficiency being the determining factor. 
While none of the graduate level teachers talked about this problem, two did talk about a unique problem that was completely opposite of the grading curve. Two of the graduate school teachers said that the lack of a grading curve, one teacher used pass/fail and the other didn't use a grading curve, made it difficult to create a rigorous course that would truly benefit graduate level students. Both teachers stated that the students expected to pass or receive a high mark and often didn't expect to do a lot of homework. One teacher went as far as to say that this attitude was fostered by the department, as the EAP course was expected to take a back seat to the other courses that students were taking.

Another obstacle that four undergraduate teachers brought up was the problem of class size. Three teachers stated that 25-30 students were in each class and felt that this large number of students made it difficult to give enough time to each student, especially for feedback. The three undergraduate teachers that taught smaller classes, around 15 students, said that they were satisfied with the class size and thought it was ideal for conducting this type of course.

Lastly, one of the major obstacles that was brought up by both graduate and undergraduate teachers was the lack of support and understanding from their departments and universities. Many teachers cited lack of understanding and coordination between their department and the various major departments as a huge obstacle. This lack of communication often prevented teachers from knowing which skills students need for their future classes and jobs. In addition, a few teachers felt that the school saw their courses as a necessary evil, and didn't really care about what when on in the course as long as the course was listed as an EAP course.

Despite all of these obstacles and issues, most of the teachers felt that despite the problems and restrictions, that they enjoyed the class and that the class was beneficial to the students, although not as beneficial as they would like it to be in some cases. Some more specific findings and their implications for current and future instructional contexts for the future are discussed in the next section.

\section{Discussion \& Future Directions \\ 6.1. Discussion}

The interviews with the teachers highlighted many issues and concerns regarding the teaching of EAP at the tertiary level in Korea, but also showed some ways in which changes could be made to improve the current situation. Overall, four main areas were for discussion and growth were highlighted: teacher beliefs and practices, the combining of mixed majors, and mixed levels, specifically low-level students in classes, the importance of needs analysis and addressing the opinions of the students, and the institutional beliefs and obstacles created by these beliefs.

First, the interviews highlighted areas of teacher beliefs and practices that could bolster the development of EAP courses even given institutional limitations. Several of the undergraduate instructors identified student needs as a key determinant of course goals, with $\mathrm{J}$ specifically referring to skills needed for business and future careers. Lee (2014) referred to the practical value of ESP courses for career opportunities, and as something the students also felt was important, and there is room for teaching practices in current EAP courses to better reflect this. Overall, the growth of EAP (and ESP) classes is an opportunity for teachers be self-reflective and analyze what they are teaching and how they are teaching it. The majority of ELT teachers moving into EAP, whether native or non-native speakers, whether working in English L1 contexts or not, initially approach teaching EAP as being much the same as they would, or used to, approach teaching EFL or EFL (Hamp-Lyons, 2018). Teachers themselves must look at EAP as a unique chance to help students develop skills that can't be developed in most General English courses and among this sample of teachers, several were looking at ways to provide outcomes that are more relevant to their EGAP courses.

On the question of curriculum design, one of the things that many instructors expressed concern about was the fact that many of their classes are filled with students from various majors and with various abilities. Regarding the challenge of teaching these heterogeneous groups, many teachers expressed the belief that the students from various majors creates some limitations on what type of course can be taught. If teachers have students from various majors, some felt that it was difficult to go beyond teaching basic academic skills and general academic vocabulary (for example from the corpus-based skills texts some instructors were required to use.) Requiring assessments to be based on student-selected content from their studies was something some instructors felt was beneficial, as opposed to requiring a more proficiency-based essay. R, A and K agreed that such assessments which utilized general academic writing and speaking skills did benefit some students. Teachers might be able to conduct such general EAP classes, but a priority should be put on dividing EAP courses according to major, something which already is in place at the institutions several instructors teach at.

A concern that was expressed repeatedly was that many classes contained students of various levels of proficiency, which left lower-proficiency students struggling with course content. A more extreme view was that EAP classes were best suited for more proficient learners. This is possibly the result of the belief that language learning is an incremental process, and that students require a certain level of proficiency to benefit from EAP classes, something that Hyland points out flies in the face of second-language acquisition research (2018). Nonetheless, in practice, teachers do face difficulties in incorporating the needs of lower-proficiency students into mixed classes. For this, teachers must consider how they can approach scaffolding so that skills 
can be taught to low proficiency students "because of a basic orientation in EAP towards teaching to the target rather than the students' current level (Alexander, 2012).

The needs of the students are important for curriculum design, but the question of whether these courses benefit students also needs to consider the students' views of these courses. $\mathrm{R}$ reported that while students admitted they did have much support with English, many did not feel the need to take extra classes for that purpose if it meant increasing workloads. Even the idea of a class to help with the type of tasks related to their majors or future careers received a mixed response. Additionally, if universities continue not to separate students by ability, then they must question the ethics of enforcing a grading curve in a class of mixed abilities.

However, almost all the undergraduate instructors agreed on the need to gain a better understanding of student needs and "wants" (Chan, 2018) to judge the effectiveness of teaching approaches and methods. From the surveyed instructors, there was an acknowledgement of their role as "needs assessor" needs to inform teaching practices. Specifically identifying student needs and wants is an important priority for EAP instructors to develop, and suggests that Lee's conclusions about student attitudes towards EAP (Lee, 2014) can be explored through refinements to EGAP courses, and also test claims that have been used to advocate CBI courses (Kwon, 2012; Song, 2006).

On an institutional level, while the realities about administrative attitudes alluded to by Lee (2014) are relevant to the Korean context, universities can take steps to address a few of the key issues on the implementation of EAP courses and how these fit into their overall approach to students' education. Administration priorities based on government evaluations and rankings Lee (2014) have resulted in rapid changes to programs, but EAP departments and faculty have much to offer, starting from an assessment of teacher objectives, practices and beliefs, and about instructional design and how we engage our students.

The fact that many teachers reported that they teach EGAP courses, and that these do show potential benefits for some students, is an indication that in some cases these courses are evolving in the right direction. Specifically pertaining to EAP, the ideal would be for university administrators to consider offering a range of EAP courses to better meet student needs at different stages in their academic careers. An EGAP course, with its emphasis on academic expectations and skills that can be considered applicable across disciplines, can serve as a valuable foundation for $1^{\text {st }}$ year students. Rather than impose blanket requirements for EAP courses, universities must ask how to make EAP courses beneficial for students of all levels and all majors, and how to create a range of curriculum offerings that meets these needs.

Institutions must also look at the needs of the students and talk with professors from multiple departments to see what the students need to succeed in their future major courses, particularly for EMI courses where there is little or no language support. If such support means the instruction of more specialized skills and understanding of texts, discourse and vocabulary is required, then universities must consider offering such ESAP or CBI courses to support students' in using English in conjunction with their studies. However, there were only a few reports of initiatives and of department faculty being willing to collaborate with EAP instructors on curriculum design, so if modifications are to be made in course offerings it may well be that it is left to instructors to create these. The marginalization of EAP practitioners and the continued view of EAP as a remedial course separate from core instruction (Hylands, 2018) is something that will take the cumulative effort of initiatives from those in the field in Korea to counter and turn into a more positive outcome.

\subsection{Future Directions}

Such initiatives are the responsibility of EAP practitioners to enact, and here we suggest directions from research that have potential applications here. Firstly, these directions begin with an analysis of our own views of what these could and should be. This means a more thorough examination of teaching contexts, instructional practices, and especially beliefs, as they pertain to instructing more genre- and discipline-specific topics and different proficiency levels - the BALEAP Competency Framework can provide benchmarks by which to develop instructional design. From this survey, prevailing beliefs about teaching lower-proficiency students in EAP contexts do show a disconnect with theory (Hyland, 2002), but the opportunity exists to create variations of such courses that scaffold learning (Wilson, 2016) even for these lower levels and to validate EAP as a worthwhile pursuit in the Korean teaching context.

Attempts should be made to better determine the needs of students, and Lee (2014) analysis of student preferences for GE or EAP/ESP courses can be an important consideration in this. While the original basis for the study, perceptions of EMI courses, is certainly valid, issues such as the need for and utility of EAP courses in the broader context of students' studies can be explored, in conjunction with instruction aimed at lower levels (Alexander, 2012) and tapping into the greater motivation that higher-proficiency students potentially have (Nakano \& Kusada, 2010). In both these cases, instruction of general or more specific forms of discourse can be situated in discipline-related topics, as discussed below, and the perceived benefits of learning-transfer to major courses (James, 2014) can be explored further.

If a needs analysis is to be properly undertaken, student beliefs about EAP (and EMI) and motivation are only a part of the equation; attempts need to be made to determine how EAP courses can be better integrated 
into the broader university curriculum, in other words, what are the needs of the departments themselves. The distinction made by Flowerdew (2016) between EGAP for undergraduates (which can have objectives related to real-world contexts) and ESAP for graduates (an academic focus) can provide some guidance for specific course proposals. An example is one undergraduate course discussed by A in this study - this course arose as a result of request by a faculty member, designed to combine two stated objectives the department had for students in that major, with applications for both academic requirements and future professional activities. As $\mathrm{A}$ and D also pointed out, the further development of ESAP courses to support graduate studies and research goals can also be further structured and tailored, especially considering language users' increased knowledge of content.

The stages of syllabus design Chan (2018) outlines for ESP can be applied both for EGAP courses and ESAP in various disciplines. For EGAP this can mean ascertaining more general "target situations" (Chan, 2018 ) in the same vein as an ESP model, and developing instructional methods and assessments related to this. In the case of ESAP, an example based on Wingate (2012) call for genre-based approached for writing instruction in selected contexts using student models is certainly applicable in EGAP teaching contexts for Engineering and Sciences, for example. If the trend of maintaining EMI courses as a core of instruction continues, for the universities to rectify the current lack of support with content, "parallel" ESAP (Anderson, 2014) and adjunct CBI courses (Brinton, 2012) can be set up with collaboration from department faculty.

\section{Limitations}

The limitations to this study begin with the sample size. The sample was a convenience sample and although it was considered by the researchers to be a good representation of the situation that many tertiarylevel instructors face while trying to teach EAP courses at Korean universities, it is still a small sample and it did not include all areas of the teaching context here. In addition to the sample, only qualitative data was collected though the semi-structured interviews, which, despite yielding much useful information across widely varying perspectives, also required much follow up for more specific insights. The main focus of this study was to get a brief overview of the EAP situation at the Korean tertiary level and to allow for future studies that will utilize a larger sample size and collect both quantitative and qualitative data in more specific areas, such as teacher beliefs and practices, as well as student preferences and needs as mentioned above, and these interviews did provide some important departure points for further research.

\section{Conclusion}

The shift from GE to EAP/ESP at the tertiary level in Korea is relatively recent, and in many ways, is still seeking clear direction. This shift came about from universities ostensibly placing greater emphasis on students' “external goals such as getting a job or pursuing academic achievement” (Lee, 2014) but was made without clear evidence of the effectiveness of such a shift, and was also underpinned by administrative priorities which have led to a somewhat mixed bag of course offerings and outcomes. The results of this survey have shown that EAP in the Korean context remains largely in the realm of EGAP, based on the apparent belief of university administrators that such "academic skills" courses would be sufficient to equip students with what they need to use English in their fields. Limited findings on teacher beliefs and practices merit further investigation, especially as they relate to course objectives and teaching approaches for genrebased pedagogies and for lower-proficiency learners. However, it has been shown that certain initiatives have the potential to improve both undergraduate and graduate instruction, with an increasing focus on more practical needs at the undergraduate level, and greater support for the demands of academic skills at the graduate level. Greater progress in the customization of EAP undergraduate courses for discourses and skills of particular majors, ideally to support rather than replace existing EGAP courses, as well as the implementation of CBI courses (adjunct, modified or hybrid) (Brinton, 2012) would have benefits for a wide range of students. At the graduate level, EAP writing courses to complement the increasing awareness of discipline specialists of the need for supporting students in research and publication would better equip these students to pursue academic inquiry in English.

\section{References}

Alexander, O. (2012). Exploring teacher beliefs in teaching EAP at low proficiency levels. Journal of English for Academic Purposes, $11(2)$, 99-111.

Anderson, R. (2014). A parallel approach to ESAP teaching. Procedia-Social and Behavioral Sciences, 13, $194-202$.

Basturkmen, H. (2010). Developing courses in English for specific purposes. Basingstoke: Palgrave Macmillan.

Belcher, D. D. (2006). English for specific purposes: Teaching for perceived needs and imagined futures in the worlds of work, study and everyday life. TESOL Quarterly, 4O(1), 133-156.

Benesch, S. (2001). Critical English for academic purposes: Theory, politics and practice. Mahwah: NJ: Lawrence Erlbaum.

Brinton, D. (2012). Content-based instruction in English for specific purposes. In C. Chapelle (Ed.), The Encyclopedia of Applied Linguistics. New York: Blackwell Publishing.

Chan, S. C. C. (2018). Proposing and illustrating a research-informed approach to curriculum development for specific topics in business English. English for Specific Purposes, 52, 27-46. 
Chang, H. J. (2009). A study on curriculum development for general English for the ABBEEK Program. English Language E Literature Teaching, 15(1), 327-348.

Dudley-Evans, T., \& St John, M. J. (1998). Developments in English for specific purposes. Cambridge: Cambridge University Press.

Falaus, A. (2017). The current challenges of teaching ESP. IOP Conference Series: Materials Science and Engineering, $200: 012059$. Flowerdew, J. (2016). English for specific academic purposes (ESAP) writing: Making the case. Writing ङْ Pedagogy, 8(1), $5-32$.

Flowerdews, J., \& Peacock, M. (2001). Issues in EAP: A preliminary perspective. In J. Flowerdew \& M. Peacock (Eds.), Research perspectives on English for academic purpose. Cambridge: Cambridge University Press.

Gillett, A. J. (2011). What is EAP? Retrieved from http://www.uefap.com/bgnd/eap.htm. [Accessed August 14, 2018 ].

Hamp-Lyons, L. (2018). Why researching EAP practice. Journal of English for Academic Purposes, 31, A3-A4.

Hyland, K. (2002). Specificity revisited: How far should we go now? English for Specific Purposes, 21(4), 385-395.

Hylandd, K. (2006). Representing readers in writing: Student and expert practices. Linguistics and Education, 16(4), 363377 .

Hylandp, K., \& Hamp-Lyons, L. (2002). EAP: Issues and directions. Journal of English for Academic Purposes, 1(1), 1-12.

Hylands, K. (2018). Sympathy for the devil? A defense of EAP. Language Teaching, 51(3), 383-399. Available at: $10.1017 /$ So261444818000101

James, M. A. (2014). Learning transfer in English-for-academic-purposes contexts: A systematic review of research. Journal of English for Academic Purposes, 14, 1-13.

Kwon, S. H. (2012). Development of general English courses at the university level: Analysis of curricular and learner needs. English Language \& Literature Teaching, 18(4), 21 1-235.

Lee, Y. J. (2014). General English or ESP/EAP? Rethinking college students' needs for GE and ESP/EAP. English Language Eं Literature Teaching, 20(1), 133-156.

Nakano, M. K., \& Kusada, N. (2010). Motivation and content in an EAP classroom. Journal of Soka Women's College, 40, $153-167$.

Richards, J. C. (2006). Communicative language teaching today. Cambridge: Cambridge University Press.

Savignon, S. J. (2007). Beyond communicative language teaching: What's ahead? Journal of Pragmatics, 39(1), $207-220$.

Seong, M. H., Chang, H. J., \& Kim, H. J. (2007). Needs analysis of university students for the general English curriculum development. Modern English Education, 8(3), 31 8-340.

Song, B. (2006). Content-based ESL instruction; long-term effects and outcomes. English for Specific Purposes, 25(4), 420437.

Wette, R. (2014). Teachers' practices in EAP writing instruction: Use of models and modeling. System, 42, 60-69.

Wilson, K. (2016). Critical reading, critical thinking: Delicate scaffolding in English for academic purposes. Thinking Skills and Creativity, 22, 256-265.

Wingate, U. (2012). Using academic literacies and genre-based models for academic writing instruction: A 'literacy' journey. Journal of English for Academic Purposes, 11(1), 26-37. 